\title{
PENINGKATAN PELAYANAN KERETA API PANGRANGO RELASI BOGOR-SUKABUMI
}

\author{
Drs. Hotland Silaban, M.Si \\ Dosen STTD \\ Jl. Raya Setu Km. 3,5 Cibuntu, \\ Cibitung, Bekasi 17520 \\ Telp./fax. 0218254640 \\ Drs. Bardi, MM \\ Dosen STTD \\ Jl. Raya Setu Km. 3,5 Cibuntu, \\ Cibitung, Bekasi 17520 \\ Telp./fax. 0218254640
}

\author{
Sugita, MM \\ Dosen STTD \\ Jl. Raya Setu Km. 3,5 Cibuntu, \\ Cibitung, Bekasi 17520 \\ Telp./fax. 0218254640 \\ Dr. Drs. Ujang Cahyono, MM \\ Dosen STTD \\ Jl. Raya Setu Km. 3,5 Cibuntu, \\ Cibitung, Bekasi 17520 \\ Telp./fax. 0218254640
}

\begin{abstract}
Public transport services of passenger trains relation Bogor-Sukabumi provided to meet the transportation needs hinterland Bogor-Sukabumi which generally are workers who need transportation back and forth so no need to spend the night in the city where work, but it is also as transport continued for workers both private and government working in Jakarta who use transit commuter line however transport such advaced yet meet passenger satisfaction because after getting off the train Jabodetabek, they are not immediately able to move the train but still have to travel by foot or using two-wheeled vehicles to the station Bogor, because the location of the station for further transport is located opposite the Bogor station. And the road that separates the very congested with vehicles due to primary arterial road. So it takes a longer time when compared with the straight lane at the same station that is the station where the commuter line Bogor one end to the trip.
\end{abstract}

Keywords: Public Transport services, Commuter Line

\begin{abstract}
ABSTRAKSI
Pelayanan angkutan umum penumpang kereta api relasi Bogor - sukabumi disediakan untuk memenuhi keutuhan angkutan daerah hinterland Bogor dan sukabumi yang umumnya adalah para pekerja yang membutuhkan angkutan pergi pulang sehingga tidak perlu bermalam dikota tempat bekerja,selain itu juga sebagai angkutan lanjutan bagi para pekerja baik srwasta dan pemerintah yang bekerja di jakarta yang menggunakan angkutan komuter line.namun demikian angkutan lanjutan tersebut belum memenuhu kepuasan penumpang karena setelah turun dari kereta api jabodetabek mereka tidak langsung dapat berpindah kereta tetapi masih harus melakukan perjalanan bisa dengan berjalan kaki dan ataupun menggunakan kendaraan roda dua ke sta.Bogor dua ,karena lokasi Stasiun untuk angkutan lanjutan tersebut berada diseberang Stasiun Bogor satu dan jalan yang memisahkan dua Stasiun tersebu sangat padat dengan kendaraan karena jalan tersebut merupakan jalan arteri primer dalam kota Bogor. sehingga membutuhkan waktu yang lebih lama bila dibanding dengan langsung pindah jalur pada Stasiun yang sama yakni sta Bogor satu dimana komuter line mengakhiri perjalanan
\end{abstract}

Kata Kunci: Pelayanan Angkutan Umum, Komuter Line 


\section{IDENTIFIKASI MASALAH}

Dari latar belakang tersebut diatas teridentifikasi permasalahan sebagai berikut :

1. Pelayanan penumpang di sta.awal pemberangkatan yakni di sta Bogor dua belum memuaskan masyarakat pengguna jasa

2. Pada saat jam sibuk pelayanan peron dan Stasiun Bogor 2 kurang memuaskan

3. Pelayanan perpindahan penumpang antar Stasiun sangat berbahaya bagi penumpang karena harus menyeberang jalan dengan lalu lintas yang padat

4. terbatasnya akses pada ruang keluar dan masuk Stasiun Bogor dua mengakibatkan banyak menumpuknya orang dihalaman Stasiun

5. Ruang untuk penumpang keluar dan masuk serta transit kurang luas dan belum tertata dengan baik

6. Informasi yang menyatakan bahwa keberangkatan kereta api dari Bogor ke suksbumi masih sangat kurang dan hampir dikatakan tidak ada

\section{BATASAN MASALAH}

Penelitian ini dilakukan terbatas hanya pada kemudahan akses pelayanan KA di Stasiun Bogor,kinerja Stasiun Bogor dua dan ketersediaan KA relasi Bogor - sukabumi

\section{RUMUSAN MASALAH}

1. Upaya-upaya apa yang harus dilakukan agar pelayanan akses naik dan turun penumpang dapat memuaskan pelanggan KA relasi Bogor - Sukabumi ?

2. Upaya upaya apa yang harus dilakukan agar akses keluar masuk Stasiun Bogor dua dapat melayani pelanggan dengan baik ?

3. Upaya upaya apa yang harus dilakukan agar kinerja Stasiun pemberangkatan dari Stasiun Bogor dua dapat optimal ?

4. Upaya upaya apa yang harus dilakukan untuk memenuhi meningkatnya pelanggan penumpang KA relasi Bogor - sukabumi yang terkait dengan ketersediaan KA ?

\section{TUJUAN}

Tujuan dari penelitian ini adalah untuk meningkatan kinerja pelayanan angkutan lanjutan kereta api penumpang umum relai Bogor - sukabumi. 


\section{URGENSI PENELITIAN}

Sebagai bahan masukan dan pertimbangan bagi instansi terkait dalam rangka mempercepat peningkatan kinerja pelayanan kereta api penumpang umum relasi Bogor suka bumi.

Penelitian yang terkait dengan detail desain engineering yang dilakukan oleh konsultan pt ka meliputi penelitian dibidang soil test seperti sondir dan boring dalam rangka untuk mengetahui daya dukung tanah melalui peneyelidikan dilaboratorium terhadap jenis dan sifat tanah pada daerah jalurkereta api lintas Bogor - sukabumi sehingg perbaikan dapat dilakukan untuk peningkatan daya dukung tiang dan tubuh badan jalan kereta api tersebut

\section{BAGAN ALIR}

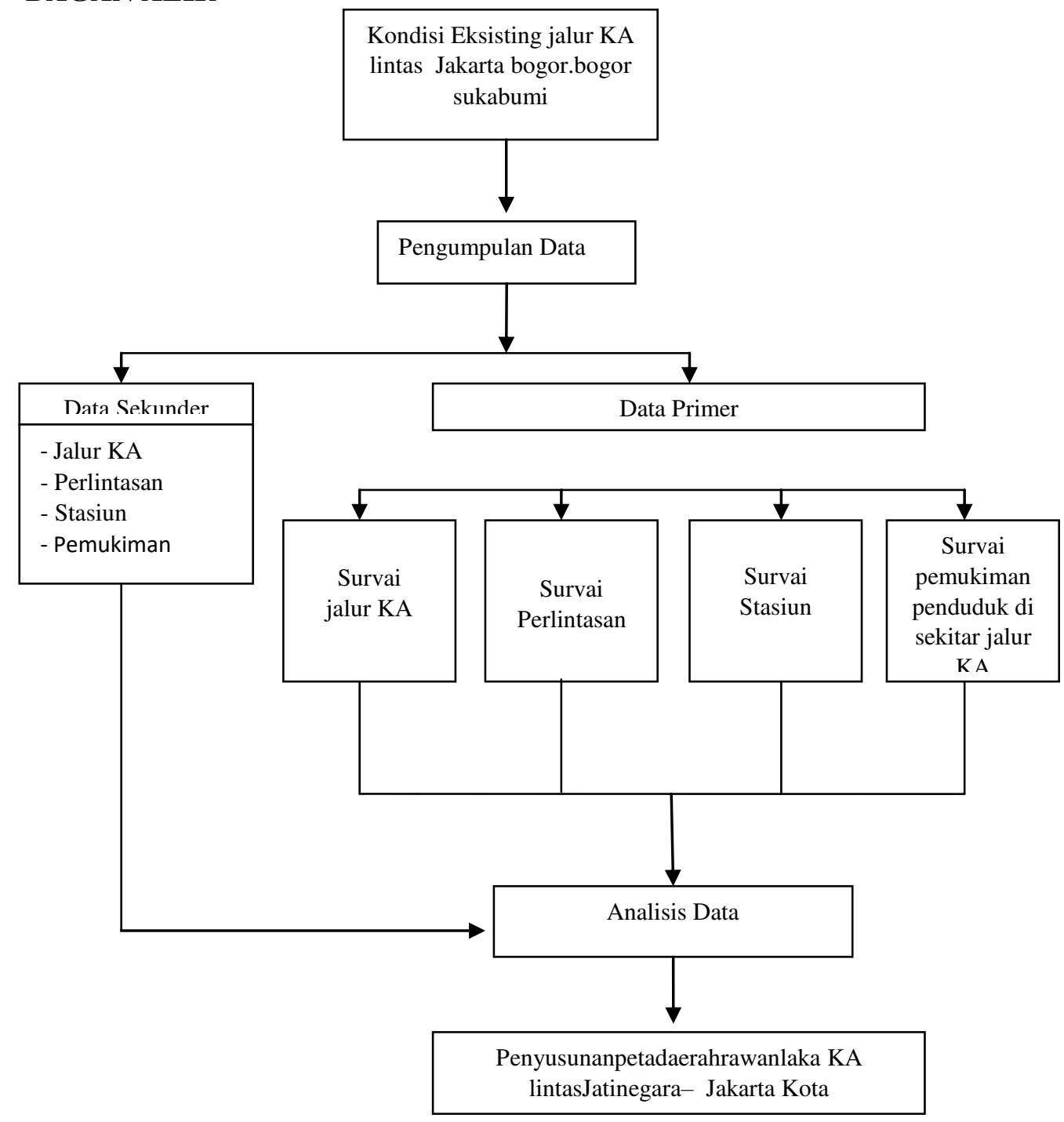

Gambar 1 Bagan Alir Penelitian 


\section{HIPOTESIS}

Pengujian hipotesis dalam penelitian ini digunakan Hipotesis deskriptif dengan yakni menilai kekuatan variabel mandiri dengan tidak mempersoalkan perbandingan dan hubungan dari variabel melalui rumusan masalah adalah sebagai berikut :

Berapakah tingkat pelayanan yang dihasilkan oleh kinerja emplasemen dan akses penghubung dari Bogor satu ke Bogor dua serta ruang masuk dan keluar Stasiun ? Dari rumusan masalah tersebut dituangkan dalam rumusan hipotesis deskriptifnya adalah

Tingkat pelayanan yang dihasilkan oleh kinerja emplasemen adalah 80 $\%$.akses penghubung kurang memadahi dan ruang keluar dan masuk stasiun Bogor Paledang.

Sedang analisa hubungan digunakan melalui analisa hubungan korelasi gamma melalui variabel teramati tingkat kepuasan dan tinggkat pendidikan.

\section{ANALISA DAN PEMBAHASAN}

\section{Analisa Deskriptif}

1. Analisa Kinerja Akses

Akses Stasiun Bogor satu - sta.Bogor dua /Paledang

Dari hasil pengamatan tentang akses untuk menuju Stasiun Bogor dua Paledang pada saat jam sibuk terlihat kurang nyaman hal ini terlihat para calon penumpang yang akan bepergian dan atau pulang kerja dengan tujuan Stasiun antara sampai dengan Stasiun sukabumi harus keluar dari Stasiun Bogor satu terlebih dahulu kemudian menyeberang jalan nasional dalam kota /arteri primer 4 lajur 2 arah dengan median untuk menuju Stasiun Bogor dua Paledang yang kondisinya sangat padat dengan $\mathrm{v} / \mathrm{c}$ ratio $83,85 \%$. Sementara itu bagi calon penumpang yang sama sekali belum pernah bepergian ke Stasiun sukabumi dan berasal dari penumpang komuter line maka calon penumpang tersebut harus bertanya dahulu ke petugas keamanan untuk mendapatkan informasi tentang bagaimana cara membeli tiket ,dimana letak Stasiun Bogor dua dan bagaimana agar sampai ke Stasiun Bogor dua Paledang .dengan melihat kondisi ini jelas terlihat akses ke Stasiun pemberangkatan Bogor dua Paledang sangat minim informasi dan tidak efisien karena calon penumpang banyak kehilangan waktu untuk melakukan perjalanan tambahan untuk menuju Stasiun pemberangkatan dan menanyakakan informasi yang seharusnya sudah tersedia dengan lengkap dan baik di pintu keluar Stasiun Bogor satu dan untuk 
itu akses penumpang dari Bogor satu menuju Bogor dua Paledang dapat dikatakan kurang memadai dengan kinerja $200 \%$ terkait waktu atau dengan kata lain calon penumpang harus kehilangan waktu 20 menit yang seharusnya dapat digunakan untuk beristirahat dan atau beraktifitas lain yang lebih bermanfaat, untuk lebih jelasnya disampaikan gambar denah akses dari Stasiun Bogor satu ke Stasiun Bogor dua Paledang.

Keterangan :
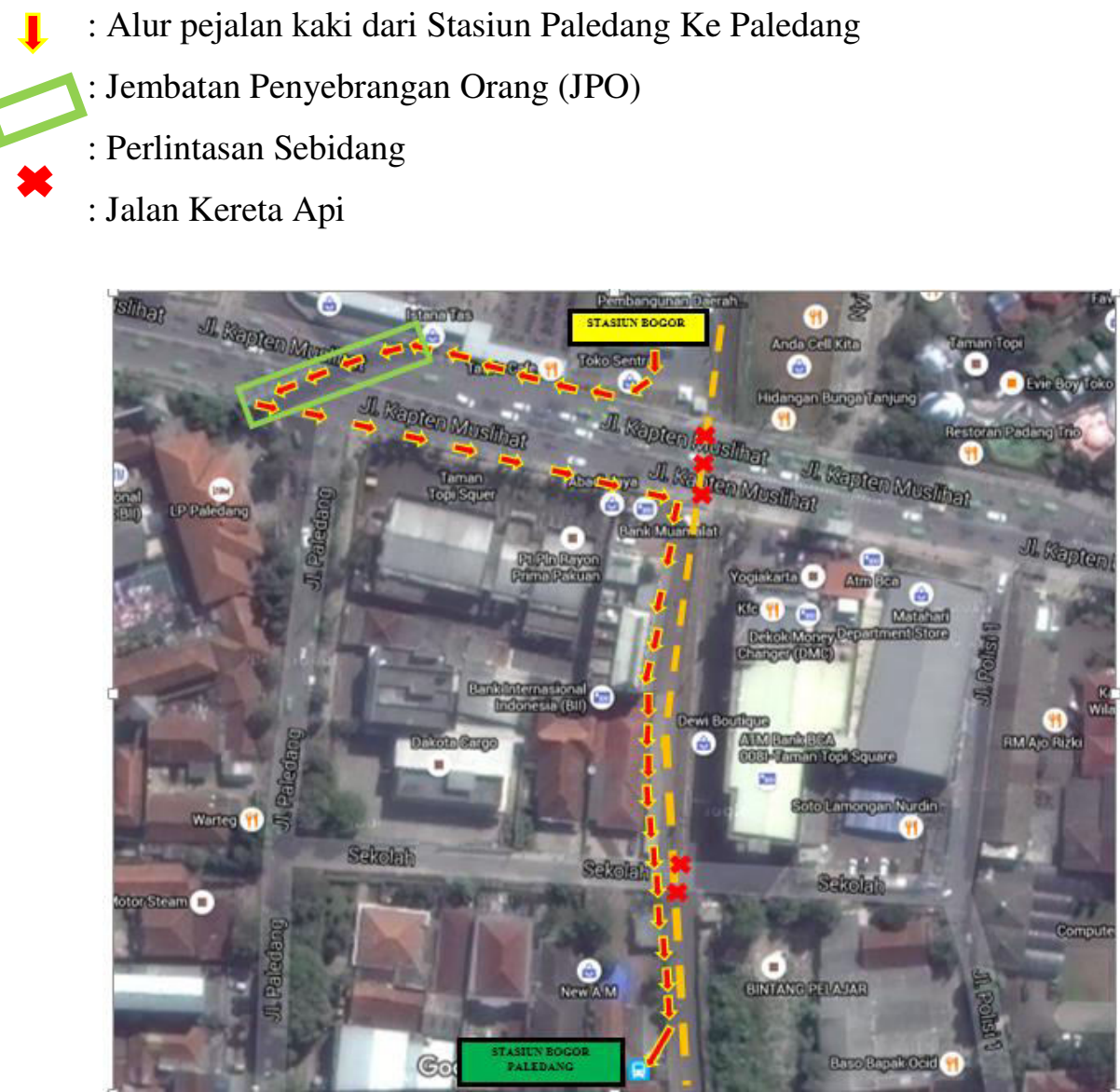

Gambar 2 Denah Akses Dari Stasiun Bogor Satu Ke Stasiun Bogor Dua Paledang Akses keluar dan masuk Stasiun Bogor/Paledang

Akses untuk keluar dan masuk di Stasiun Bogor dua Paledang terlihat kurang memadai yakni dengan akses jalan yang diperkeras dengan lebar 5 meter dan jarak sampai dengan menuju Stasiun Bogor dua Paledang sekitar 300 meter dan merupakan jalan buntu dan hanya dilalui oleh orang yang bejalan dan kendaraan roda dua dan tidak mempunyai lapangan parkir karena lahan dipakai untuk berjualan makanan dan minuman,sementara itu dimulut jalan masuk ke Stasiun Bogor dua Paledang banyak kendaraan angkutan kota dan ojek yang banyak menunggu,menaikan dan menurunkan penumpang sehingga menambah kurang baiknya akses tersebut. dengan melihat kondisi 
yang demikian makan akses keluar dan masuk Stasiun Bogor dua dapat dikatakan kurang memadai dan untuk lebih jelasnya disampaikan gambar denah akses keluar dam masuk Stasiun Paledang dua Bogor.

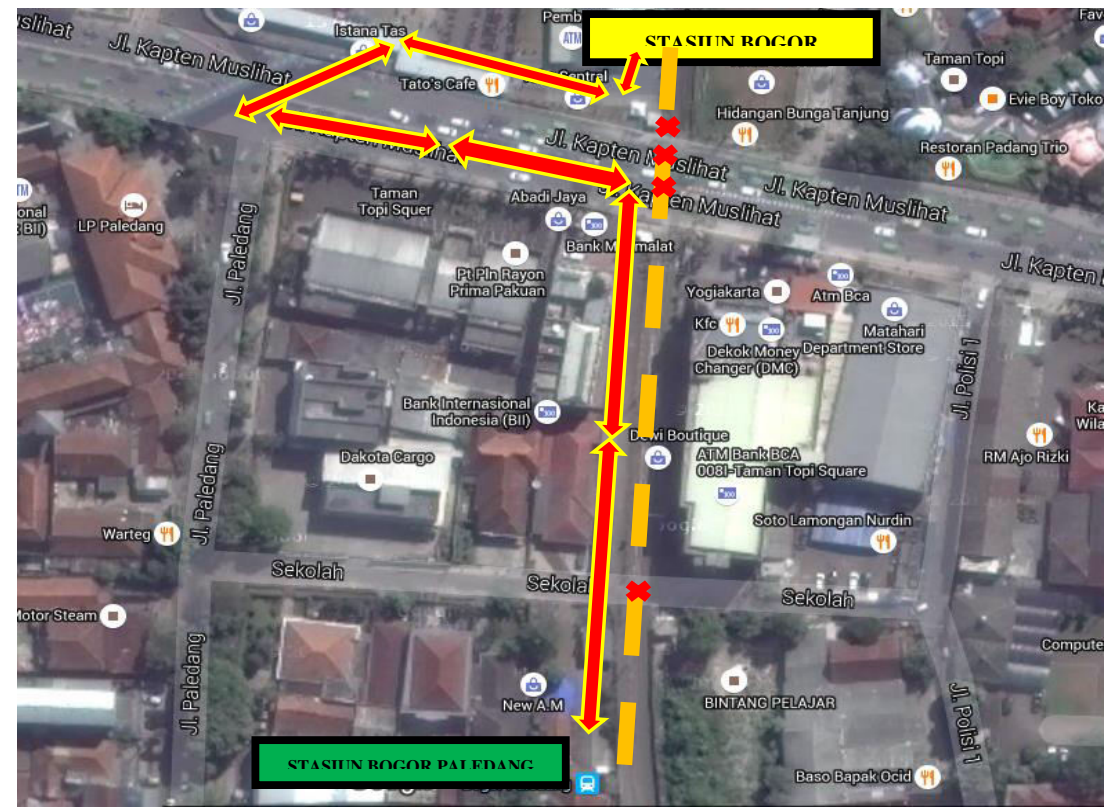

Gambar 3 Denah akses keluar dan masuk Stasiun Bogor Paledang

\section{Analisa Kinerja Emplasemen}

a. Stasiun Bogor

Fasilitas emplasemen di Stasiun Bogor satu tersedia tujuh sepur yang dipergunakan untuk melintas langsung dan langsir kereta api pangrango serta transit sekitar 168 kereta api komuter line dan juga tempat kereta api komuter line menginap di Stasiun Bogor dengan waktu operasi dari jam 04.00 sampai dengan jam 01.00.sedang kinerja Stasiun Bogor dalam 1 jam operasi adalah 70,52 \% dan hanya digunakan untuk kedatangan dan pemberangkatan kereta api komuter line lintas jabodetabek. Dengan waktu terpendek untuk naik turun penumpang sekitar 5,58 menit dan waktu terpanjang sekitar sampai dengan 15,85 menit.

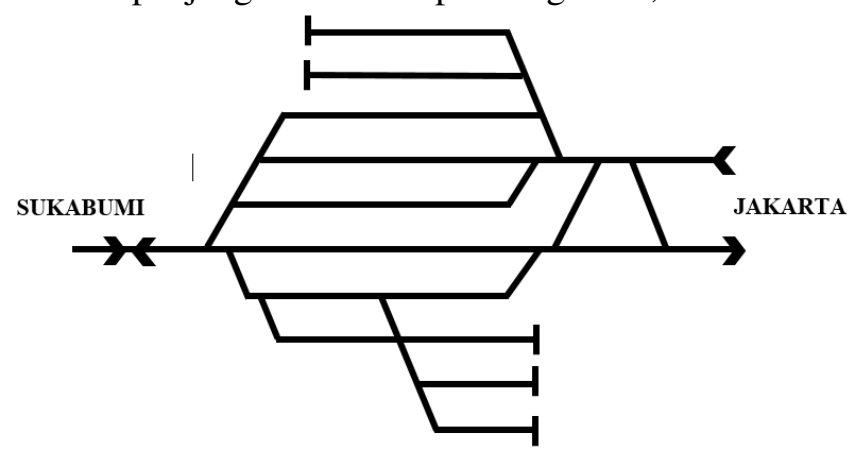

Gambar 4 Emplasemen Stasiun Bogor satu 
b. Stasiun Bogor dua /Paledang

Fasilitas emplasemen di Stasiun Bogor dua /Paledang tersedia dua sepur yang dipergunakan untuk melintas langsung dan langsir kereta api pangrango dengan waktu operasi dari jam 06.00 sampai dengan jam 20.00 dan jam pemberangkatan kereta api adalah jam 07.55 ,jam 12.55 dan jam 18.30 ,sementara itu peron tersedia dalam emplasemen juga kurang memadai karena dalam waktu sibuk satu jam pemberangkatan kinerja peron $85,70 \%$ namun peron akan segera bersih dalam waktu 4 s/d 7 menit karena penumpang sudah naik dalam kereta api. sedang kinerja jalur pada emplasemen Stasiun Bogor dua Paledang dalam 1 jam operasi adalah $12,64 \%$, dan hanya digunakan untuk kedatangan dan pemberangkatan kereta api pangrango.

JAKARTA

SUKABUMI

\section{PERON STASIUN PALEDANG}

Gambar 5 Emplasemen Stasiun Bogor dua /Paledang

c. Stasiun cicurug

Fasilitas emplasemen di Stasiun cicurug tersedia dua sepur yang dipergunakan untuk melintas langsung dan transit kereta api pangrango sedang peron tersedia untuk naik dan turun kereta api dengan waktu operasi dari jam 05.00 sampai dengan jam 22.00.sedang kinerja jalur pada emplasemen Stasiun cicurug adalah $14,52 \%$ karena kereta api yang melintas dalam 1 jam operasi hanya ada satu kereta api

JAKARTA

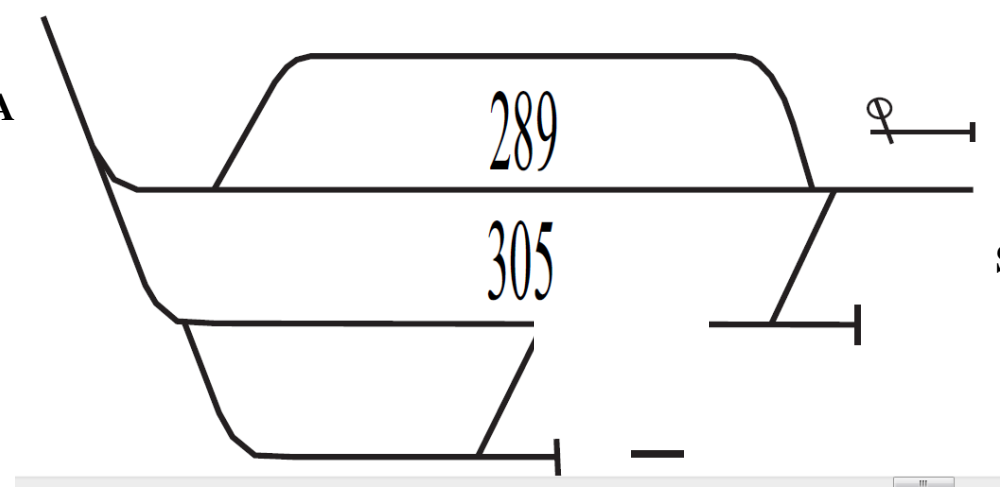

SUKABUMI

Gambar 6 Emplasemen Stasiun cicurug 
d. Stasiun karang tengah

Fasilitas emplasemen di Stasiun karang tengah tersedia dua sepur yang dipergunakan untuk melintas langsung dan transit kereta api pangrango dengan waktu operasi dari jam 05.00 sampai dengan jam 22.00. sedang kinerja jalur pada emplasemen Stasiun adalah $14,52 \%$ dan kinerja peron juga masih rendah yakni sekitar $3,33 \%$.

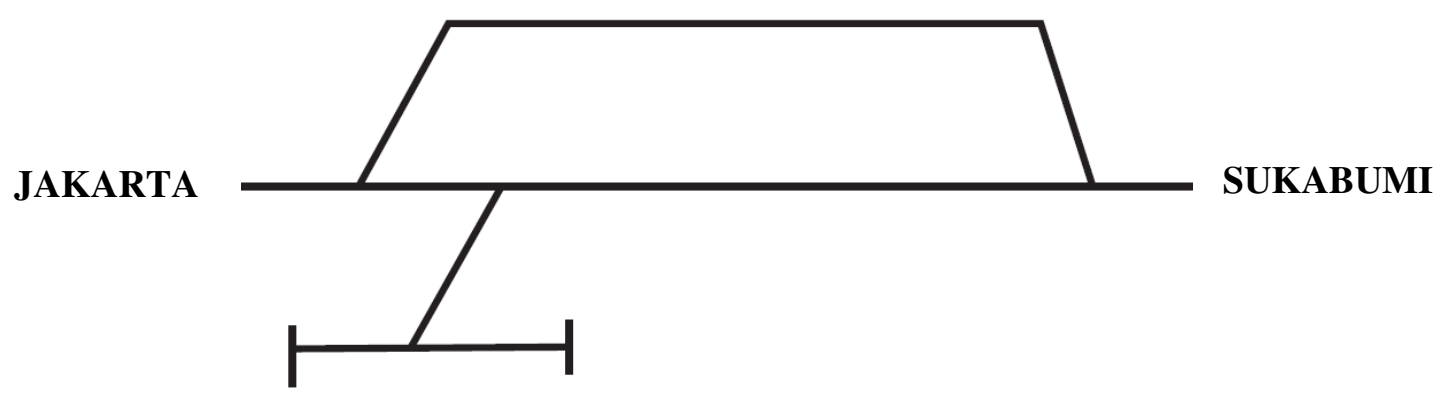

Gambar 7 Emplasemen Stasiun karang tengah

e. Stasiun cisaat

Fasilitas emplasemen di Stasiun cisaat tersedia dua sepur yang dipergunakan untuk melintas langsung dan transit kereta api pangrango dengan waktu operasi dari jam 04.00 sampai dengan jam 22.00.sedang kinerja Stasiun cisaat adalah 14,52\% dan kinerja peron adalah $4,52 \%$.

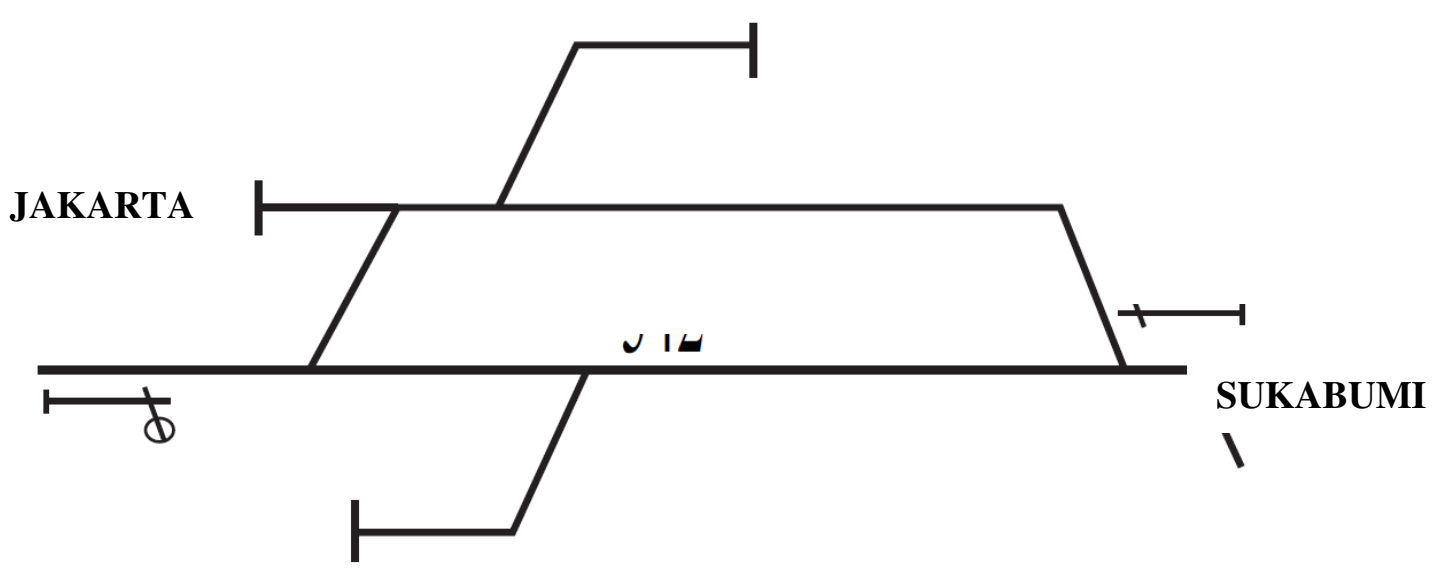

Gambar 8 emplasemen Stasiun cisaat 
f. Stasiun sukabumi

Fasilitas emplasemen di Stasiun sukabumi tersedia empat sepur yang dipergunakan untuk menginap , langsir dan pemberangkatan dan kedatangan kereta api pangrango dengan waktu operasi dari jam 04.00 sampai dengan jam 22.00. dengan jam pemberangkatan dari Stasiun sukabumi adalah jam 05.00 ,jam 10.04 dan jam 15.01 sedang kinerja jalur emplasemen Stasiun sukabumi pada satu jam sibuk adalah $16,67 \%$ dan mempunyai kinerja peron pada satu jam sibuk adalah 79,65 $\%$.secara rinci emplasemen Stasiun dapat dijelaskan seperti gambar tersebut dibawah ini

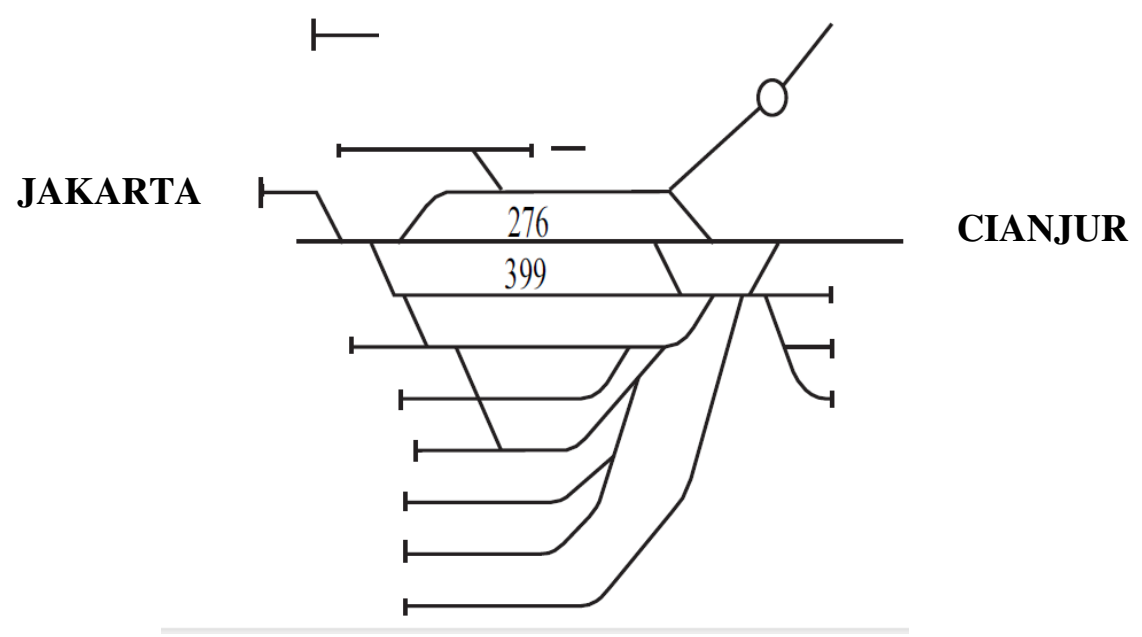

Gambar 9 Empalsemen Stasiun sukabumi

\section{Analisa Kinerja Jalur}

a. Jalur Bogor - Bogor /Paledang

Jalur kereta api lintas Bogor Satu - Bogor dua /Paledang mempunyai satu sepur yang berfungsi untuk melintas dan langsir kereta api jarak pendek pangrango sedang kinerja jalur pada lintas ini adalah hanya sekita $14,27 \%$

SUKABUMI

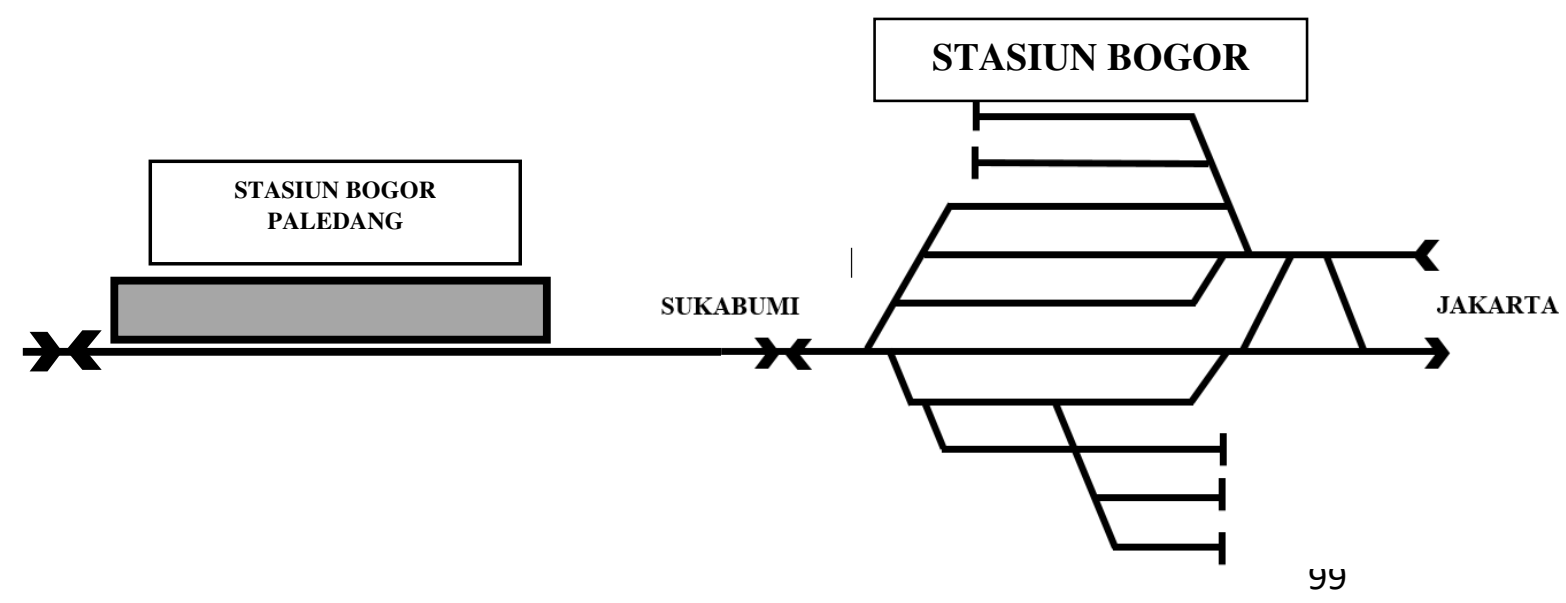


Gambar 10 Jalur kereta api lintas Bogor satu - Bogor dua /Paledang

b. Bogor/Paledang - sukabumi

Jalur kereta api lintas Bogor /Paledang - sukabumi terdapat Satu sepur dan melintas lebih dari sembilan setasiun yakni Stasiun batu tulis - sta.maseng sta.cigombong - sta.cicurug - sta.parang kuda - sta.cibadak - sta.karang tengah sta.cisaat dan Stasiun sukabumi dengan kinerja jalur 14,27 \% karena pada jalur ini hanya beroperasi satu kereta api pangrango pulang pergi.

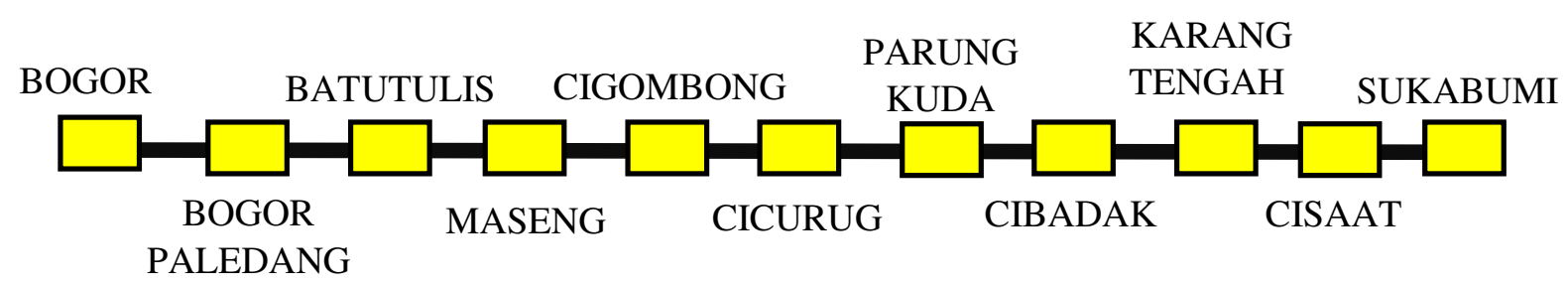

Gambar 11 Jalur kereta api lintas Bogor - Sukabumi

\section{Analisa Kerja Sarana}

Analisa kinerja sarana ka pangrango untuk relasi Stasiun Bogor satu sta.sukabumi sudah cukup baik dengan jarak $56 \mathrm{~km}$ serta kecepatan ka $40 \mathrm{~km} / \mathrm{jam}$ ditambah dengan pemberhentian di setiap Stasiun antara yang telah ditentukan dengan pelayanan sinyal mekanik. Stasiun sukabumi harus keluar dari Stasiun Bogor satu terlebih dahulu kemudian menyeberang jalan yang kondisinya sangat padat dengan v/c ratio 83,85 $\%$, sementara penumpang komuter line yang turun di Stasiun Bogor satu dan penumpang yang akan naik dari daerah sekitar Bogor yang akan melanjutkan dan bepergian ke Stasiun sukabumi pada bulan oktober jam 18.30 hari senen berjumlah 285 orang ,selasa 297 orang ,jumat 269 orang ,sabtu185 orang dan hari minggu berjumlah 227 Orang.Sedang jumlah penumpang dari Stasiun sukabumi pada bulan oktober jam 05.00 pada hari senen 296 orang ,selasa 281 orang,jumat 285 orang ,sabtu 215 orang dan minggu adalah 275 orang sedang kapasitas tersedia dari kereta api yang melayani rute untuk relasi Bogor - sukabumi adalah 400 tempat duduk dengan rincian tiga kereta $\mathrm{K} 3$ dan satu kereta eksekutip dengan rata rata jumlah penumpang $60 \mathrm{~s} / \mathrm{d} 80 \%$ dari Bogor menuju sukabumi pada waktu pagi hari yakni jam 07.55 dan sore hari jam 15.01 dari sukabumi menuju Bogor sedang untuk hari kerja dan jam 18.30 dari Bogor dan jam 05.00 
dari sukabumi dengan rata rata penumpang naik adalah $100 \%$.sementara itu jumlah penumpang naik dari Stasiun Bogor dua Paledang dan Stasiun sukabumi dalam satu hari operasi adalah sebagai berikut :

a. Dari Bogor hari senin jam 07.55 : 172 orang,jam 12.55 :128 orang dan $18.30: 286$ orang

b. Dari sukabumi hari senin jam $05.00: 298$ orang, $10.04: 158$ orang dan $15.50: 129$ orang.

\section{Analisa Hubungan}

Untuk lebih mengetahui keapuasan pelanggan yang terkait dengan tingkat pelayanan yang sudah diberikan oleh penyedia, berikut analisa hubungan analisa hubungan melalui koefisien korelasi gamma $(\gamma)$ hubungan antara tingkat pendidikan dengan tingkat kepuasan pelayanan

Tabel 1 hubungan antara tingkat pendidikan dengan tingkat kepuasan pelayanan

\begin{tabular}{lccc}
\hline \multirow{2}{*}{ TINGKAT KEPUASAN } & \multicolumn{3}{c}{ TINGKAT PENDIDIKAN } \\
& SD & SMA & SARJANA \\
\hline PUAS & 25 & 18 & 10 \\
KURANG PUAS & 12 & 13 & 15 \\
TIDAK PUAS & 8 & 17 & 32 \\
\multicolumn{1}{c}{ JUMLAH } & $\mathbf{4 5}$ & $\mathbf{4 8}$ & $\mathbf{5 7}$ \\
\hline
\end{tabular}

Penyelesaian :

a. Nilai koefisien korelasi gamma $(\gamma)$

$$
\begin{aligned}
& \sum \mathrm{fa}=(25)(13+15+17+32)+(18)(15+32)+(12)(17+32)+(13)(32) \\
& =3775 \\
& \sum \mathrm{fi}=(10)(12+13+8+17)+(18)(12+8)+(15)(8+17)+(13)(8) \\
& =1339 \\
& \gamma=\frac{\Sigma F a-\Sigma F i}{\Sigma F a+\Sigma F i} \\
& =\frac{3775-1339}{3775+1339} \\
& =0,4763
\end{aligned}
$$


b. Nilai $\gamma$ adalah 0,4763 memeberikan kesimpulan bahwa antara pendidikan dan tingkat kepuasan mempunyai hub yang positif.

\section{KESIMPULAN DAN SARAN}

\section{Kesimpulan}

Dari hasil analisa dan pembahasan yang terdiri dari analisa kinerja akses ,emplasemen dan kinerja jalur serta kinerja sarana angkutan kereta api dengan relasi Bogor - sukabumi maka dapat ditarik kesimpulan sebagai berikut :

1. Kinerja akses dari sta. Bogor satu ke Bogor dua Paledang teramati kurang baik karena penumpang ka pangrango harus menambah waktu dengan berjalan menyeberang kearah selatan menuju Stasiun pemberangkatan dan atau pemberhentian Bogor dua /Paledang

2. Kinerja jalur pada emplasemen Stasiun Bogor dua Paledang dan Stasiun antara serta Stasiun sukabumi sangat rendah yakni sekitar 12,64\% .sementara itu kinerja peron Stasiun Bogor dua /Paledang dan Stasiun sukabumi pada saat satu jam sibuk cukup tinggi yakni sekitar 79,65\%

3. Kinerja jalur lintas boggor sukabumi juga sangat rendah karena hanya dilalui oleh satu kereta api yakni sekitar $14,27 \%$

4. Kinerja sarana melalui kereta api pangrango cukup baik yakni sekitar $40 \% \mathrm{~s} / \mathrm{d} 60 \%$ pada jam 10.04 dan jam 15.01 dari Stasiun sukabumi dan jam 07.55 dan jam 12.15 dari Stasiun Bogor sedang untuk jam 05.00 dari Stasiun sukabumi dan jam 18.30 dari Stasiun Bogor kinerja sarana bahkan mencapai $100 \%$ hal ini dikarenakan pada jam tersebut adalah jam terbaik pada saat lima hari kerja.

\section{Saran}

Agar kinerja jaringan prasarana dan jaringan pelayanan angkutan kereta api relasi Bogor sukabumi dapat optimal maka disarankan hal hal sebagai berikut :

1. Pembuatan akses yang baik melalui jalur khusus bisa berupa jembatan dan atau terowongan langsung dari Stasiun Bogor satu menuju Bogor dua Paledang dan atau pemindahan ke jalur satu pada jam jam tertentu untuk keberangkatan dan kedatangan ka pangrango di Stasiun Bogor satu.

2. Menambah kecepatan ka pangrango sehingga dapat mengurangi waktu tempuh sehingga waktu tempuh menjadi satu jam yakni dengan pembenahan prasarana jalur ka dan sintelist secara bertahap 
3. Disediakan papan informasi yang jelas serta ketersediaan loket di Stasiun Bogor satu untuk mempermudah akses calon penumpang ka pangrango. 